Article

\title{
Public Perception of Vernacular Architecture in the Arabian Peninsula: The Case of Rawshan
}

 \\ 1 BRE Centre for Sustainable Engineering School of Engineering, Cardiff University, Cardiff, CF24 3AB, UK; \\ RezguiY@cardiff.ac.uk \\ 2 Department of Architectural Engineering, Faculty of Engineering, Al-Baha University, \\ Al-Bahah 65527, Saudi Arabia \\ 3 Built Environment and Sustainable Technologies (BEST) Research Institute, School of Civil Engineering and \\ Built Environment, Liverpool John Moores University, Liverpool L3 3AF, UK; M.W.Ahmad@ljmu.ac.uk \\ * Correspondence: AlelwaniR@cardiff.ac.uk or rsalelwani@gmail.com
}

Received: 16 July 2020; Accepted: 26 August 2020; Published: 31 August 2020

\begin{abstract}
This research extends Hasan Fathy's (1986) principle of vernacular architecture by focusing on the Rawshan through an investigation of two criteria: aesthetics and energy efficiency. The paper discusses the views of both the Saudi public and key decision-makers on reviving vernacular architecture in the context of Saudi Arabia's rapidly developing economy, characterized by relatively high rates of energy consumption and $\mathrm{CO}_{2}$ emissions. This research explores (a) the interaction in domestic buildings of Saudi occupants with their windows, and how these are perceived as an interface with the external environment; (b) awareness and knowledge of the use of shading elements (such as Rawshans) to reduce the use of artificial lighting while maintaining indoor privacy; (c) Saudi awareness of, and familiarity with, the Rawshan as a vernacular element and a secular architectural tradition; and (d) Saudi views on the revival of traditional architectural elements with a focus on the Rawshan. An online survey $(n=812)$ was conducted across Saudi Arabia complemented by interviews with expert decision-makers $(n=23)$ to (a) assess criteria such as privacy, aesthetics, daylight, ventilation, and energy consumption in Saudi residences and (b) investigate the level of acceptance of an optimized retrofitted Rawshan design.
\end{abstract}

Keywords: Rawshan; vernacular architecture; privacy; ventilation; energy efficiency; aesthetics; daylight; decision-makers; public perception

\section{Introduction}

Vernacular architecture is a broad, multidisciplinary field that involves cultural, social, economic, and architectural considerations. Moreover, vernacular architecture tends to concern occupant needs in terms of indoor comfort [1]. The main factors that influence vernacular architecture include local environmental conditions, materials, and construction techniques as well as building occupant needs [2]. In most cases, conventional buildings are built to house and protect inhabitants from environmental factors while maintaining a level of harmony with the surrounding environment and prevalent culture [3-5]. Vernacular architecture exemplifies the highest form of sustainable building, as it typically employs exclusively locally sourced materials and environmentally friendly technologies [6]. Additionally, among the most popular local (Arabian Peninsula) vernacular architectural elements is a Rawshan that embodies Arab-Islamic values. Historically, the Rawshan traces its roots to Egypt's Mamluk and Ottoman periods (1517 1905) [7-9]. Moreover, the Rawshans were used in older Middle Eastern cities in general, and the Western Region of Saudi Arabia in particular. Rawshans address five main functions: light and airflow control, reducing temperature and increasing air humidity, 
and respecting occupant privacy [7]. The Rawshan is an architectural element constructed of wooden lattices and screens $[7,8]$. Given that Rawshans comprise three-sided boxes, they provide resting areas for one person reclining at full-length. In terms of the indoor environment, Rawshans can assist in cooling and humidifying residences. When exposed to air currents, the wood of a Rawshan absorbs, retains, and releases water, and, after, this wood is warmed by sunlight and releases any retained humidity [7].

In accordance with the local context, several variations of Rawshans have been developed. The meaning, functions, and regional characteristics of the Rawshan are covered in the various definitions discussed hereafter. In the Oxford Dictionary of Architecture [10], a Rawshan is defined as a timber "lattice screen", often intricate, geometric, and beautiful in Islamic architecture. The term originally translated from the Arabic language, as different spellings such as Rawshan, Roshan, or Rowshan, were found in many published articles. Additionally, in Arabic language, a Rawshan is a singular and Rawasheen is a plural.

However, Salloum [11] illustrated the similarities and differences between Rawshans and Mashrabiyyah. The author maintained that a Mashrabiyyah is considered part of a Rawshan, namely its window screen.

The study explores public perception and level of acceptance of Rawshans as well as intervention strategies for reducing energy consumption. Following this introduction, the paper provides a review of related literature. The methodology that underpins the research is then described in Section 3. Section 4 presents the study results, discussed in Section 5. Section 6 elaborates on the limitations of this research, while Section 7 provides concluding remarks and presents directions for future work.

\section{Literature Review}

Resembling a bay window, a Rawshan is typically constructed from oak, ebony, or mahogany. The projected depth of a Rawshan ranges from $0.4 \mathrm{~m}$ to $0.6 \mathrm{~m}$, with a projected height of between $2.7 \mathrm{~m}$ and $3.5 \mathrm{~m}$ and a width of between $2.4 \mathrm{~m}$ and $2.8 \mathrm{~m}$. However, Rawshans can often be larger than these dimensions, depending on occupant needs. For example, a larger Rawshan can accommodate a sleeping couple. There are four main types of Rawshans: (a) single layout, (b) linear vertical layout, (c) linear horizontal layout, and (d) corner layout, as illustrated in Figure 1 [12].



Figure 1. Typical Rawshan types. Source: [12].

Fathy [7] has enclosed the functions of a Rawshan within five criteria: passage of light, control of airflow, increase in humidity, reduction in temperature, and respect of privacy. Any designed and constructed Rawshan must comply with these criteria. These five criteria are taken into account in this research, and augmented with two additional criteria, namely energy consumption and aesthetic in order to assess occupants' needs in the first stage of designing a Rawshan. Many scholars have attributed several values to the Rowshan, including social, aesthetic, environmental, and energy efficiency. 
Social value is the most significant as it plays an important role in Muslim houses. The middle eastern form of Islamic culture imposes a strict segregation between males and females, and as such, women are required to maintain modesty and privacy from unrelated males. This Islamic tradition has been reflected in the form, structure, and function of domestic and public spaces, to allow female occupants to experience outdoor life without being observed. The Rawshan is a true reflection of this tradition and has enjoyed a secular importance in the middle eastern domestic architecture. This criterion has been investigated by many scholars in the same field $[5,7,8,11,13-17]$. However, other researchers, for example Samuels [18], overlooked the social aspects in their research.

Evidence of the aesthetic value in the design of the Rawshan or Mashrabiyyah has been shown in Hedjazi houses. The Hedjazi house without the Rawshan was described as a large block provided with extensive fenestration. In other words, without the ornamental Rawshan, it looks deprived from architectural values [9]. Thus, nowadays a Rawshan has become an old legacy used by modern architects. The Rawshan industry has grown and flourished artistically more than functionally.

Most of the previously published research focussed on the environmental aspects of a Rawshan (e.g., daylight and thermal comfort). Al-Shareef, 1996a and M. Hariri, 1992 have validated the environmental values of the Rawshan. Conversely, Aljofi [19] confirmed that the critical assessment of Rawshan thermal output, with its natural ventilation capacity, should always be pursued to produce environmentally sensitive screens of the Rawshan. On the other hand, Gelil M and Badawy [20] prevented the revival of the Rawshan's (Mashrabiyyah) screen in countries such as Egypt due to air pollution. Nevertheless, the ventilation factor seems to be perceived as a limitation in the Western Region of Saudi Arabia (Hedjaz) as discussed in Chapter 5, Section 5.3.2. Karamata [21] proposed a flexible design of a Rawshan screen (Mashrabiyyah) that maximizes the diffusion of sunlight and views to the outside, while minimizing solar gains. The author utilized an experimental and software-based theoretical method to validate experimental results [21].

In terms of energy efficiency, related research involved the evaluation of a screen of the Rawshan (Mashrabiyyah) without taking into consideration the whole element. Moreover, all scholars recommend using the perforated screen to defuse sunlight while achieving energy efficiency. Many studies focus solely on solar screens and their perforation. Chan and Tzempelikos [22] studied the relationship between solar screens and daylight performance in buildings located in tropical and subtropical areas. Sherif, El-Zafarany [23] examined solar screens forming part of a Rawshan, identifying that they could achieve up to a 30\% reduction in the total energy consumption in South and West directions. In studying movable and fixed shading systems, Francesca and Marco [24] attempted to optimize daylight and energy performance in office zones, identifying that adequate daylight and energy performance were given by fixed shading systems with an adapted inclination angle and overhang. Freewan [25] studied the impact of external shading devices on daylight and thermal performance of offices located in Jordan, concluding that daylight and visual comfort were considerably improved by external shading devices, while the temperature decreased accordingly. Erell, Kaftan [26] studied improved use of daylight for visual comfort and energy conservation in offices within clear-sky areas by evaluating several shading strategies, identifying that shading blinds achieved visual comfort, but required regular adjustment. Kotbi [27] found out in his experiment that using perforated screens (Mashrabiyyah) in a school in Saudi Arabia improves the illuminance distribution and spatial ratio between near and far spaces. Shin, Lee [28] attempted to find the optimum position of Venetian blinds in a residential apartment to allow sufficient daylight by changing the slat angle and shading height, with the results recommending that the rotation angle and height should be designed to protect windows from low angle sunlight.

Thus, by further reviewing the abundant literature in the field of vernacular architecture with a focus on the Rawshan, a clear gap has been identified in the understanding of the perceived social and environmental usefulness of the Rawshan, and its role in promoting comfort and energy efficiency.

In fact, many researchers have investigated the characteristics of Rawshans to determine their environmental benefits. Some studies have focused on the daylight levels of rooms that involve 
traditional Rawshans in terms of maximizing and minimizing light penetration and ensuring interior privacy [7-9,11,29]. Conversely, other researchers have studied the optimum design of Mashrabiyyahs, which is considered as a component of a Rawshan [30,31]. Furthermore, Alelwani, Ahmad [32] employed genetic algorithms to investigate the optimization of Rawshan blinds for reducing energy consumption and increasing daylight penetration. Evidence from the literature suggests that future work will involve experimental and simulation studies to analyze the impacts of a Rawshan in terms of energy efficiency and thermal comfort.

\section{Methodology}

To investigate potential interest in reviving vernacular architecture in Saudi Arabia, with a focus on the Rawshan, the authors devised a research design involving (a) observation, (b) analysis of secondary data, (c) administration of a survey questionnaire, and (d) interviews with local decision-makers as illustrated in Figure 2. and explained in Section 3.1, Section 3.2, Section 3.3, and Section 3.4. As elaborated in related research $[4,33,34]$, surveys are data collection instruments that aim to reveal estimations of the prevalence of important variables. For this study, the researcher used the current Saudi population to calculate the appropriate number of completed survey responses necessary to constitute a valid sample size. As of September 2019, the Saudi population was estimated at $34,218,169$ by the Saudi Authority for Statistics, [35] with a margin of error of $4 \%$ at a $95 \%$ confidence level. According to Kruth, Leu [36] "A 95\% confidence level means that you would get the same results $95 \%$ of the time. $95 \%$ is the most commonly used confidence level but you may want a $90 \%$ or $99 \%$ confidence level depending on your survey. Decreasing your confidence level below $90 \%$ is not recommended" (see Table 1). Thus, an acceptable number of respondents was determined to be 601 [37]; however, the valid respondent total was 772 out of 812 with 40 missing of respondents.

Table 1. Sample size calculation based on SurveyMonkey website.

\begin{tabular}{cccccc}
\hline Confidence Level: & $\mathbf{8 0 \%}$ & $\mathbf{8 5 \%}$ & $\mathbf{9 0 \%}$ & $\mathbf{9 5 \%}$ & $\mathbf{9 9 \%}$ \\
\hline Z-Score: & 1.28 & 1.44 & 1.65 & 1.96 & 2.58 \\
Population Size $=34,218,169$ & & \multicolumn{5}{c}{ Sample Size } \\
$\begin{array}{c}\text { Assumed Population }(\%)=95 \% \\
\text { Margin of Error }(\%)=4 \%\end{array}$ & 256 & 324 & 426 & 601 & 1041 \\
\hline
\end{tabular}

This study was conducted as a pilot instrument for exploring traditional Saudi housing types and occupant preferences with a focus on the Rawshan and according to the following factors: privacy, daylight, thermal comfort, ventilation, and energy efficiency. The survey was designed in two main sections, one focussing on occupants of homes that contain an existing Rawshan or with experience living in environments with a Rawshan, and the other on occupants who had no experience living in structures that contained a Rawshan. This paper addresses the following research questions:

1. Question 1: What is the level of public awareness and engagement with reviving the Rawshan in Saudi Arabia?

2. Question 2: What criteria do Saudis find desirable in terms of retrofitting Rawshans?

3. Question 3: What are the opinions of key decision-makers in terms of reviving the Rawshan as an architectural element?

In addition, these questions were further broken down into subquestions aimed at both participant groups (i.e., those who had experience living with a Rawshan and those who had not). These subquestions helped suggest preferable locations for Rawshans, their optimal size and characteristics, and Saudi observations about this historical vernacular element. 


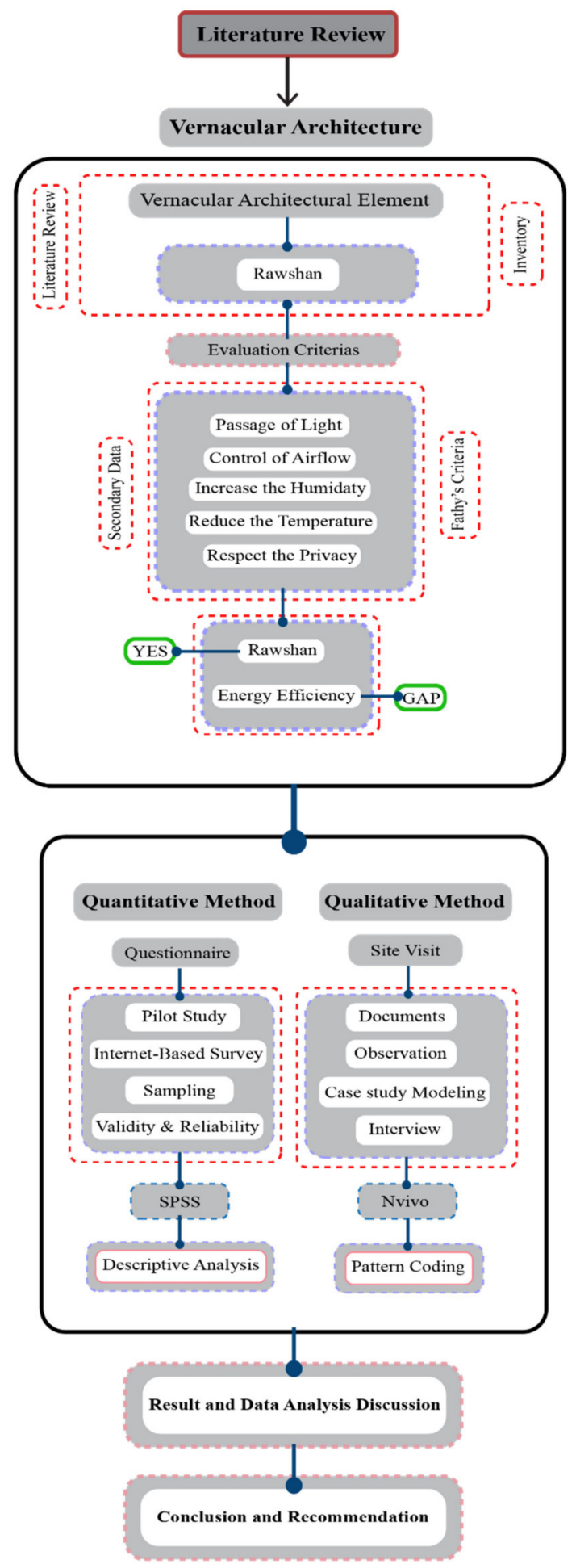

Figure 2. The methodology process.

The first two research questions were analyzed using a quantitative approach, and the third by employing a qualitative method. According to Denzin and Lincoln [38], scientists "emphasize, describe, evaluate, compare, depict, evoke pictures and make a feeling of being there for the viewer or listener.". Therefore, the authors used a combination of quantitative (i.e., questionnaire) and qualitative (i.e., interviews, documentation, and observation) tools to capture the holistic views of participants and record their interpretive reflections. Thus, these two primary data techniques were 
utilized to address the posited research questions. In addition, information related to shading device types, the rate of decline in the construction of traditional Rawshans in Saudi residential buildings, various socio-cultural factors, the views of decision-makers regarding the revival of Rawshans, and public perception was gathered. The researchers sought this additional information from people of diverse ages, education levels, and geographical locations, as is discussed below.

Given that this study was grounded in a mixed-method approach, the triangulation of its methods was essential. According to Cohen, Manion [39], triangulation is a "powerful way of demonstrating concurrent validity." For this research, methodological triangulation was achieved by applying various techniques to the same research phenomena such as quantitative (questionnaires) and qualitative (interviews, documentation, and observation). The data collection period ran from November 2018 to March 2019, during which time the steps of (i) observation, (ii) collection of secondary data (documents), (iii) distribution of questionnaires, and (iv) interviews were completed.

\subsection{Observation}

Observation was conducted in four Saudi Arabian cities: Mecca, Riyadh, Jeddah, and Al-Baha. The researchers found that the exterior and dominant residential construction styles in these cities comprised a range of traditional and contemporary Western facade components. The observation process commenced in 2016 and spanned for almost three years. The researcher originally began this process by being nonselective in his exploration, but over time, it narrowed into a concentrated observation of selective aspects of construction. Moreover, Rawshans were predominately found in Saudi Arabia's Western Region, particularly in Mecca and Jeddah Al-Taif.

\subsection{Documents}

Several types of secondary data were used to support this research, such as the history of the Rawshan, size and dimension of the Rawshan, and type of the Rawshan. This information facilitates the creation of the survey questionnaire. Alongside this, architectural drawings (including plans, sections, and façade elevations), building material properties, and electricity bills were collected [40].

\subsection{Questionnaire}

For this study, the researcher used an online survey questionnaire as the primary data collection instrument, as surveys can facilitate the collection of the perspectives of a large population in a consistent manner. As Bryman [41] discussed, survey questionnaires are those that respondents complete themselves. Online questionnaires have been used in many studies, for example, an exploration of cultural obstacles to low-energy housing in Saudi Arabia [42], and a study on decision-making regarding the form of a Mashrabiyyah designed using 3D printing technology in Bahrain [43]. In addition, this type of instrument can assist researchers in gathering data from a large number of respondents and, for this study, assisted in identifying the needs of Saudi citizens.

Participants were asked to rate their perceptions of the questionnaire items on a 5-point Likert-type scale, ranging from 1 to 5 , where $1=$ extremely important; $2=$ very important; $3=$ moderately important; $4=$ not so important; and $5=$ not at all important. The questionnaire also contained open-ended questions to enable respondents to provide comments on included items, or other significant ideas they thought were important. Demographic information such as age, gender, occupation, academic qualification, and the location (i.e., urban, suburban, or rural) was included.

The survey was designed in two main sections, (1) focussing on occupants of homes that contain an existing Rawshan or with experience living in environments with a Rawshan which reached about 199 participants and (2) occupants who had no experience living in structures that contained a Rawshan about 573 participants (see Table 2). In November 2018, the online survey questionnaire was designed, piloted, and distributed to members of the Saudi public with the aim of promoting ease of completion and rapid response rates. The questionnaire was developed in the following four stages: 
Table 2. Statistics of participants who participated in the survey.

\begin{tabular}{|c|c|c|c|}
\hline Have You Lived in a House & Has a Rawshan? & Frequency & Percent \\
\hline \multirow{3}{*}{ Valid } & Yes & 199 & 24.5 \\
\hline & No & 573 & 70.6 \\
\hline & Total & 772 & 95.1 \\
\hline \multirow[t]{2}{*}{ Missing } & System & 40 & 4.9 \\
\hline & & 812 & 100.0 \\
\hline
\end{tabular}

\subsubsection{Stage 1: Pilot Study}

Conducting pilot studies can assist researchers in verifying and testing their questions and data collection instruments [41]. For this research, the pilot study, which comprised $(n=15)$ respondents, helped the researcher in revising and omitting survey questions. Moreover, the study showed that the most important section of the questionnaire, which was initially placed at the end, would be better placed at the beginning of the survey. Thus, the pilot study findings were used to modify the final survey and improve the efficacy of its questions.

\subsubsection{Stage 2: Internet-Based Survey}

Using the Internet to conduct survey questionnaires is a common and increasingly utilized approach $[39,44]$, as it is generally a faster method of collecting data when compared to administering printed surveys [45-47] and is generally less expensive [35]. As Collins [48] observed, survey questions should be kept short and to the point. The researcher used the website SurveyMonkey (www. surveymonkey.com) to design and administer the online survey, which comprised twenty-four questions and included demographic inquiries. Respondents were anticipated to be able to complete the questions within $11 \mathrm{~min}$, and the survey was sent as a link generated from SurveyMonkey that was distributed across the country. To maximize the understanding of its questions, the survey was written in both Arabic and English. The collected survey data were analyzed quantitatively using the IBM SPSS statistics software application for Windows, Version 25.0 [49]. Descriptive statistical techniques were applied to the data to compute scale frequencies, response percentages, means, and standard deviations (SD). A descriptive study of demographic data was also carried out by calculating frequencies and percentages. Internal consistency reliability was evaluated by Cronbach's alpha $(\alpha)$ coefficient [50] that provided a single estimate of internal consistency or average correlation of questionnaire items to measure the reliability [51,52]. Many social studies suggested that a value of 0.70 is the acceptable reliability threshold $[53,54]$. For the present study, the value of Cronbach's alpha came out to be 0.799 which was acceptable as a measure of internal consistency.

Based on these considerations, the survey was divided into two sections depending on whether respondents had experienced living in a home that had a Rawshan or not. In the first section, respondents who had experience with a Rawshan answered questions related to the Rawshan and their homes. These respondents were then directed to the second section, which was to be completed by all respondents, regardless of their experience with Rawshans. This second section was divided into two supplementary sections: (a) shading device types and (b) information about light and privacy.

Cohen, Manion [39] recommendations were considered when designing the survey questions as follows:

(a) As some of the elements addressed in the questions differed in meaning across different regions of Saudi Arabia, the researcher included images to clarify their meaning.

(b) Appropriate fonts, templates, and an Arabic translation of the survey were included in order to ensure survey readability and comprehension.

(c) Question line lengths were designed to fit the screen size of smart devices. 


\subsubsection{Stage 3: Sampling}

A snowball sampling technique was utilized in distributing the survey questionnaire. This technique is a sampling approach that allows survey units to enhance their data [55-57]. This method, which is also referred to as chain-referral or link-tracing [58], is considered effective and economical [59]. This approach involves the distribution of a questionnaire to participants, who then forward it to others and so on, thus facilitating a high rate of participation. For this study, the survey was distributed via social media applications such as WhatsApp, Facebook, Twitter, Telegram, and LinkedIn [60] and was forwarded to additional participants.

\subsubsection{Stage 4: Validity and Reliability}

The researchers' colleagues at Cardiff University (Cardiff, UK) and Al-Baha University (Al-Baha, Saudi Arabia), who took part in the pilot study, deemed the survey questions and translations to be valid and reliable. Additionally, the survey was validated through peer review by native speakers of Arabic and English, respectively. Cohen, Manion [39] stated that online surveys are generally more valid and reliable than those sent by post. In addition, the researchers did not elect to use the post as the Saudi postal system has a reputation for carelessness, and most residents instead rely on email and fax machines.

\subsection{Decision-Maker Interviews}

The interview process comprised a mixed structured and semistructured method. The structured approach was used in conducting most of the interviews. The structured interviews were conducted with twenty-three experts from different sectors in Mecca, Jeddah, and Al-Baha. The purpose of these interviews was to speak with decision-making experts that have had some form of exposure or involvement with Rawshans. The selection criteria for choosing the participants included:

(a) Decision-makers responsible for granting planning consent in line with the local regulations [61].

(b) Minimum of 5-10 years of experience in a professional field of architecture, civil engineering, and urban planning.

(c) Possible knowledge about a vernacular architectural element, i.e., a Rawshan.

Participant selection for these decision-makers was also designed to cover building professionals in various Saudi government sectors. The participants held degrees ranging from bachelor's degrees to $\mathrm{PhDs}$ related to architecture, civil engineering, and urban planning. The interviewee sample included twelve architects, ten civil engineers, and one urban planner (see Table 3). The names of the interviewees are depicted by codes to easily understand the interviewees' roles and inputs in the study assessment.

Table 3. Interviewee data.

\begin{tabular}{ccccc}
\hline Number of Decision-Makers & Occupation & Organization & Degree & Code \\
\hline 1 & Architect & Al-Baha University & PhD & ArchBU \\
7 & Architect & Municipality of Mecca & Bachelor & ArchMM \\
4 & Architect & Municipality of Jeddah & Bachelor & ArchMJ \\
1 & Architect & Municipality of Al-Baha & Bachelor & ArchMB \\
1 & Civil Engineer & Municipality of Mecca & Bachelor & CiviMM \\
8 & Civil Engineer & Municipality of Jeddah & Bachelor & CiviMJ \\
1 & Urban Planner & Municipality of Mecca & Bachelor & UrbaMM \\
23 & & Total & & \\
\hline
\end{tabular}

Here, the aim was to build an understanding of the viewpoint of experts concerning an optimized retrofit Rawshan. Based on these considerations, a qualitative approach was applied to analyze the interview data. 
The collected documents provided qualitative and quantitative information that helped to build an initial understanding of the issues, limitations, and behaviour of Saudi residents regarding the use of windows, indoor-outdoor relationships with respect to windows, and community awareness of and knowledge about the use of sun-shading devices and Rawshans to reduce the use of artificial lighting during daylight hours while maintaining privacy. The documents also helped to illuminate Saudi views on the revival of vernacular architectural elements such as Rawshans. The responses were coded using NVivo12 software [62] into themes that emerged from the data. These themes were then clustered into categories along with relevant quotations from the interview transcripts. Here, relevant responses from these interview transcripts were provided.

\section{Consultation Results}

A total of 812 responses were received, of which 772 answered all survey questions. The remaining analysis is on the 772 valid responses. The table for the demographic characteristics of the respondents is given below Table 4 . The description and distribution of the respondents are described below.

Table 4. Respondents' demographic factors.

\begin{tabular}{|c|c|c|c|c|}
\hline & Variable & Scale & Frequency & Total $(\%)$ \\
\hline \multirow{26}{*}{ Valid } & \multirow{2}{*}{ Gender } & Male & 439 & 54.1 \\
\hline & & Female & 333 & 41.0 \\
\hline & \multirow{6}{*}{ Age group (y) } & $18-24$ & 67 & 8.3 \\
\hline & & $25-34$ & 269 & 33.1 \\
\hline & & $35-44$ & 224 & 27.6 \\
\hline & & $45-54$ & 114 & 14.0 \\
\hline & & $55-64$ & 78 & 9.6 \\
\hline & & $65+$ & 20 & 2.5 \\
\hline & \multirow{7}{*}{ Occupation } & Government employee & 360 & 44.3 \\
\hline & & Nongovernment employee & 104 & 12.8 \\
\hline & & Self-employed & 22 & 2.7 \\
\hline & & Student & 96 & 11.8 \\
\hline & & Retired & 84 & 10.3 \\
\hline & & Housewife & 89 & 11.0 \\
\hline & & Other & 17 & 2.1 \\
\hline & \multirow{7}{*}{ Qualification } & High school & 81 & 10.0 \\
\hline & & Diploma & 48 & 5.9 \\
\hline & & Bachelor's Degree & 371 & 45.7 \\
\hline & & Master's Degree & 176 & 21.7 \\
\hline & & $\mathrm{PhD}$ & 76 & 9.4 \\
\hline & & Prefer not to say & 81 & 10.0 \\
\hline & & Other & 12 & 1.5 \\
\hline & \multirow{2}{*}{ House owner types } & Owner & 432 & 53.2 \\
\hline & & Tenant & 340 & 41.9 \\
\hline & \multirow[t]{2}{*}{ Missing } & System & 40 & 4.9 \\
\hline & & & 812 & 100.0 \\
\hline
\end{tabular}

- Gender: About 56.9 percent of the respondents were male, and the remaining 43.1 percent were female.

- Age: $8.7 \%$ were of the age group 18 to $24,34.8 \%$ were of the age group 25 to $34,29 \%$ were of the age group $35-44,14.8 \%$ were of $45-54,10.1 \%$ were of the age group $55-64$, and only $2.6 \%$ were above 65 years of age which was the lowest.

- Occupation: $46.6 \%$ were government employees, $13.5 \%$ were nongovernment employees, $2.8 \%$ were self-employed, $12.4 \%$ were students, $10.9 \%$ of them were retired, $11.5 \%$ were housewives, and the others category was of around $2.2 \%$.

- Qualification: $10.5 \%$ had the highest qualification as High School, 6.2\% had a diploma, $48.1 \%$ (the majority) had a bachelor's degree, $22.8 \%$ had a master's degree as their highest qualification, 
$9.8 \%$ had a PhD, $1 \%$ preferred not to say their qualification, and the category of others had a total of $1.6 \%$.

- City: A table for the percentage of city distribution is represented below. The survey was collected from a total of 50 cities from which maximum responses were obtained from the city of Makkah Al Mukarramah (29.3\%), and the lowest responses were obtained from cities such as Thuqbah, Gurayat, Wadi Al-Dawasir, Tarout, Dawadmi, and Bareg (0.1\% each). Because of the 50 cities, the table will be included in the index

- House Ownership Type: Of the 772 respondents, 56\% lived in the house/apartment that they owned themselves, and $44 \%$ were staying in a rented house/apartment.

The first research question concerned the level of Saudi public awareness and engagement with reviving the use of Rawshans. Specifically, this question addressed: (a) the behaviour of Saudi homeowners regarding the use of windows and indoor-outdoor relationship with respect to windows; (b) awareness and knowledge of residential shading devices; (c) level of acceptance of a revived Rawshan as an architectural element.

\subsection{Occupant Interactions with and Perceptions of the Role of Windows}

Windows that afford a visual connection from the inside to the outside of a home (and not vice versa) are widely used in Islamic countries in general and Arabic countries in particular. Most of these countries recommend privacy as an element in residential homes. Privacy is a requirement in Gulf Cooperation Council Countries (GCCCs) such as Saudi Arabia [13,63] and Bahrain [64] and is compulsory in Kuwait [65]. As discussed previously, residential windows are strongly related to privacy in Saudi homes. In Saudi society, care is taken to protect residential interiors from the view of pedestrians through the use of interior curtains. Thus, the researchers included a question to investigate the Saudi relationship between privacy, daylight, and window use. Given that the use of Rawshan was not widely adopted in Saudi Arabia, we have decided to extend the scope of our investigation to include the concept of an opening, such as a window. This was useful to understand and infer from our consultation the perceived virtue of the Rawshan.

Survey participants were asked about the actions that they typically take with respect to windows to maintain privacy, control daylight, and reduce the use of artificial lighting. In response, 31.63\% reported that they normally open their blinds and curtains to let in natural light, turn off their artificial lights, and generally disregard privacy. Furthermore, $10.61 \%$ reported that they partly draw their curtains and use artificial lighting, which suggests partial privacy is achieved. Moreover, 55.90\% expressed that they would be willing to find a solution that helps them to better control the level of daylight while maintaining privacy, and $1.86 \%$ claimed that they employ other ways to address this issue.

\subsection{Shading Device Types and Their Awareness in the Saudi Community}

This section included images alongside each of the possible responses in order to ensure that participants accurately selected the shading device that is deployed in their homes. Moreover, this section investigated if respondents had expectations about the design of their homes. In addition, these responses were compared to the interviewees' view that foreign architects may design indiscriminately to collect their fees.

The results illustrated that types of treatment have been used by the users to avoid the sunlight, and they showed that $83.15 \%$ of survey participants employ fabric curtains, $15.61 \%$ use paper tints, and $2.32 \%$ have wooden louvers. Furthermore, $5.56 \%$ have iron grills on the front of their windows, and stained glass windows are used by $12.06 \%$ of respondents. In addition, $1.8 \%$ of participants reported that they use vertical sun shading devices, as compared with the $1.85 \%$ who report using horizontal shading devices. Finally, 3.40\% of participants reported the use of both horizontal and vertical shading devices as shading devices. From our observations, site visits, and interviews, we can assume that all Saudi homes employ at least one of the shading devices shown in Table 5. Thus, 
most of the participants reported that they use curtains to block sunlight even though their homes have external shading devices. This finding suggests that most Saudi homeowners may not have knowledge of residential design in general and residential facades in particular. As a result, we can conclude that the issue of the changing identity of Rawshans in Saudi society stems from architecture firms, specifically from foreign architectural staff, as will be explained in Section 5.5.

Table 5. Types of sun-shading devices and images.

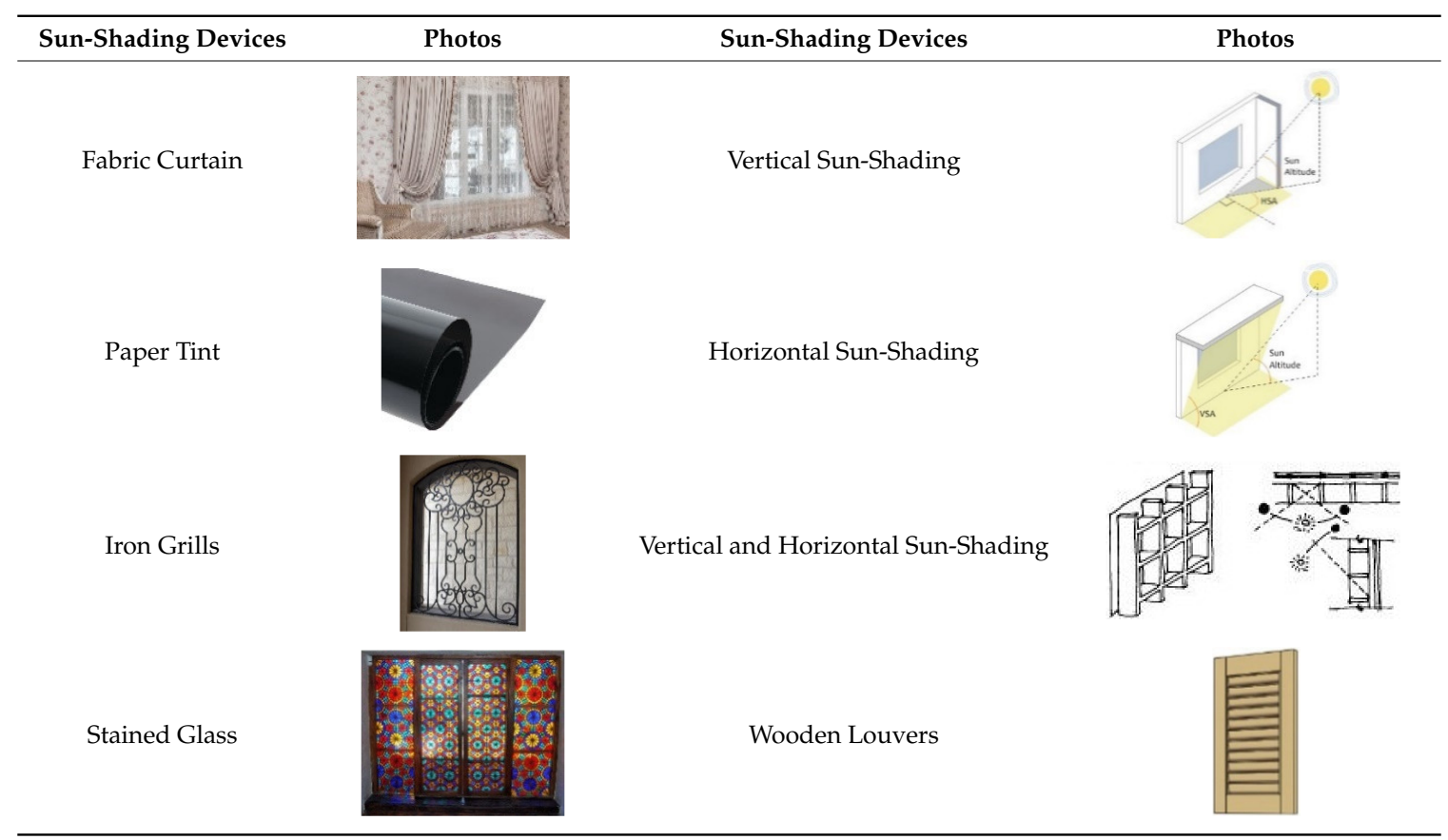

\subsection{Levels of Acceptance of the Revival of the Rawshan}

The study results show that the majority of survey respondents and all expert interviewees agreed that a revival of retrofit optimized Rawshans would be positive based on the criteria, which will be discussed latter in Section 5.6.

The second research question focused on criteria desired by Saudi residential inhabitants. Survey participants were asked a question regarding five criteria-aesthetics, daylighting, privacy, reduced energy consumption, and ventilation-with respect to their homes. For this question, participants rated their perceptions of these criteria on a 5-point Likert scale, for which $1=$ extremely important; $2=$ very important; $3=$ moderately important; $4=$ not so important; and $5=$ not at all important. The study results show that $78 \%$ of the respondents considered aesthetics to be the most important criterion for Saudi homes in general and their facades in particular. The aesthetic criterion had the highest mean score $(x=1.75)$ and the largest standard deviation $(\sigma=0.78)$. Reduced energy consumption was the second most popular criterion, with a mean score of $(\mathrm{x}=1.54)$ and an SD of $(\sigma=0.75)$. The third most popular criterion was daylight with a mean score of $(x=1.54)$ and an SD of $(\sigma=0.71)$, followed by privacy with a mean score of $(x=1.52)$ and an SD of $(\sigma=0.73)$. Finally, ventilation was reported as the fifth most important criterion with a mean score of $(x=1.46)$ and an $\mathrm{SD}$ of $(\sigma=0.75)$. Thus, the survey results show that the five criteria ranked from the most to least important were aesthetics, reduced energy consumption, daylight, privacy, and ventilation (see Table 6). These results corroborated the views of participant ArchMM, as discussed above. Thus, these findings suggest that new façades that mimic Rawshans are constructed only for pretentious and aesthetic reasons, and ignore the functionality that made them environmentally-friendly. 
Table 6. Descriptive analysis of the criteria for designing a Saudi home.

\begin{tabular}{|c|c|c|c|c|c|c|c|c|c|c|c|c|c|c|}
\hline Criteria & Extremely Important & 1 & Very Important & 2 & Somewhat Important & 3 & Not So Important & 4 & Not at All Important & 5 & Total & Mean & SD & Preference Order \\
\hline Privacy & $61.15 \%$ & 395 & $27.55 \%$ & 178 & $10.06 \%$ & 65 & $1.08 \%$ & 7 & $0.15 \%$ & 1 & 646 & 1.52 & 0.73 & 4 \\
\hline Daylight & $57.30 \%$ & 369 & $32.92 \%$ & 212 & $8.39 \%$ & 54 & $1.40 \%$ & 9 & $0.00 \%$ & 0 & 644 & 1.54 & 0.71 & 3 \\
\hline Ventilation & $66.41 \%$ & 429 & $23.22 \%$ & 150 & $8.36 \%$ & 54 & $1.55 \%$ & 10 & $0.46 \%$ & 3 & 646 & 1.46 & 0.75 & 5 \\
\hline Reducing Energy & $58.48 \%$ & 376 & $28.62 \%$ & 184 & $11.82 \%$ & 76 & $0.78 \%$ & 5 & $0.31 \%$ & 2 & 643 & 1.56 & 0.75 & 2 \\
\hline Aesthetic & $43.81 \%$ & 283 & $38.70 \%$ & 250 & $16.10 \%$ & 104 & $1.24 \%$ & 8 & $0.15 \%$ & 1 & 646 & 1.75 & 0.78 & 1 \\
\hline Other & - & - & - & - & - & - & - & - & - & & 6 & - & - & - \\
\hline
\end{tabular}


Addressing the third question required an investigation and evaluation of the views of the expert interviewees-many of whom hold Saudi government positions-in the event that retrofit optimized Rawshan design is adopted into the Saudi Building Code (SBC). As discussed previously, this question was analyzed qualitatively using NVivo Version 12 for Windows [62]. The results of this analysis show agreement between the expert interviewees with respect to adding retrofit optimized Rawshan design to the SBC (see Section 5.6 and Section 5.7).

The study results show a mean score of 2 (i.e., "very lost") with a standard deviation of 1.02 (see Table 7). Thus, these results suggest that the Rawshan has lost its identity and that the primary factor behind this loss concerns the predominant attitude of "copy-paste" seen in many contemporary Rawshan designs in Saudi Arabia and the Gulf region. Another factor that has led to the decline in the identity of Rawshans is the emergence of an "exhibitionist and extravagance culture" that favours prestige and lavish appearances, as interviewees ArchMM, ArchMJ, and UrbaMM highlighted. The experts interviewed for this study highlighted this issue and related it to the attitudes of Saudi architecture firms, particularly those who hire foreign staff without any oversight and those who use historical architectural elements in contemporary designs without considering if their functions are appropriate.

Table 7. Results of the question regarding the loss of identity for Rawshans.

\begin{tabular}{|c|c|c|c|c|c|c|c|c|}
\hline $\begin{array}{l}\text { Extremely } \\
\text { Lost (1) }\end{array}$ & $\begin{array}{c}\text { Very } \\
\text { Lost (2) }\end{array}$ & $\begin{array}{l}\text { Somewhat } \\
\text { Lost (3) }\end{array}$ & $\begin{array}{l}\text { Not So } \\
\text { Lost (4) }\end{array}$ & $\begin{array}{c}\text { Not at All } \\
\text { Lost (5) }\end{array}$ & $\begin{array}{l}\text { Minimum } \\
\text { Statics }\end{array}$ & $\begin{array}{l}\text { Maximum } \\
\text { Statics }\end{array}$ & Mean & S.D. \\
\hline $42.59 \%$ & $22.88 \%$ & $28.63 \%$ & $4.03 \%$ & $1.87 \%$ & 1 & 5 & 2 & 1.02 \\
\hline
\end{tabular}

The best way to reach this coexistence is to revive Fathy's principles and to add the two criteria that emerged as results in this research: aesthetics and reduction in energy consumption. The vernacular Rawshan was designed to provide human comfort and support the environment, and had it been developed for other purposes, such as blind emulation or trade, it would not have been considered true architecture. As one interviewee (ArchBU, 2019) reported, "the passive cooling characteristics of the Rawshan and its ability to control light and air flow has inspired the UK-based company Postler and Ferguson to design their microclimates project ... . This gives architects the power to revive this element [the Rawshan]."

\section{Discussion}

For this study, the authors regarded themes as categories that were inferred through analyzing the collected data. These themes cover the research under discussion, build on codes, and create a basis for researchers to understand the theoretical aspects of their collected data [41]. Thus, this process can contribute to bodies of knowledge. Coding, in turn, is an important task that investigators use to examine their collected data in order to best categorize information under certain themes. Bryman [41] discusses two-stage coding as a process in which the first stage consists of categorizing unstructured material gathered from interviews, while the second concerns assigning numbers to these categories.

For this study, a process of pattern coding [66] was used to define the emerging themes, patterns, and explanations that emerged from the qualitative data analysis [67]. Pattern coding helps researchers to group large quantities of information into analytical units that are organized around the research questions. The survey data analysis assisted in corroborating the qualitative issues that arose from the studies. The interview approach was used to address the third research question of this study.

The interview questions followed themes that emerged from the literature review and were categorized into the following topics:

(a) Comfort and satisfaction of those having experience with a Rawshan;

(b) Location of a Rawshan;

(c) Comparison of electricity bills;

(d) Comparisons between Rawshans and Mashrabiyyahs; 
(e) Identity of the Rawshan;

(f) Factors influencing the decline in the use of Rawshans;

(g) Factors influencing the adoption of Rawshans;

(h) Impacts on building regulations.

In addition, an iterative reading and assessment of participant data allowed additional pattern codes to be added, such as energy consumption, spatiality, and aesthetics. For example, while coding the interview data, it was evident that certain keywords reoccurred. The survey data were also analyzed using statistical methods that helped to corroborate the qualitative questions that emerged from the research process. These pattern codes are discussed below.

\subsection{Comfort and Satisfaction}

The survey questions related to occupant comfort and satisfaction levels led to a number of subcodes, including privacy, light control, thermal comfort, ventilation, and respect for religion.

\subsubsection{Privacy}

Vernacular architecture, along with providing a thermally comfortable indoor environment, has other advantages (e.g., a sense of privacy). Islam, a widely practised religion in the region, also dictates that Muslims should respect other people's privacy, especially their neighbors. Moreover, Islamic buildings are intended to show several of its values, such as privacy and architectural styles. Traditionally, Rawshans were also constructed to segregate women from the gaze of men, which means that their use respects privacy. However, most contemporary construction criteria have resulted in buildings that have lost this sense of identity and character. In addition, related studies $[8,9,68]$ have identified privacy as the most important criterion for a Rawshan. This finding was corroborated by those of the present study, as $61.15 \%$ of participants strongly agreed that privacy is an extremely important characteristic, and only $1.23 \%$ believed that privacy is not an important factor for vernacular architecture in Saudi Arab. This was also confirmed by the interviewees, who stressed that privacy is an important factor in the Saudi society that should be reflected in residential design. Conversely, Rawshans form a functional transition between the inner and outer environments of residential structures. They enable residents to see the outside world while preserving their privacy [68]. Moreover, 17 out of the 23 of the expert government decision-makers interviewed indicated that privacy was the most important criterion required for designing retrofit Rawshans (nine of them had an experience with Rawshans and eight had not). For example, ArchMM (2019) stated that "Privacy, daylight, ventilation and reduced energy use are extremely important. They must be applied in residential buildings, especially in Islamic and Arab countries ...".

\subsubsection{Thermal Comfort, Ventilation, and Light Control}

Evaporative cooling is among the most effective methods of cooling buildings in hot climates [69], provided that given air flows are strong enough to disperse released air vapour and enable heat transfer. Thus, as constant and continuous inner airflow are essential in cooling buildings in hot climates, any Rawshan must be designed and sized appropriately. For this research, the respondents considered ventilation to be an extremely important criterion in the design of Saudi residences. The study results show that $66.41 \%$ of participants reported that ventilation is extremely important, $23.22 \%$ considered it to be very important, $8.36 \%$ deemed it moderately important, and $1.5 \%$ believed that is was not important. On the other hand, only five interviewees who had experience with a Rawshan stated that it provided adequate ventilation. One participant stated that "ventilation, privacy, and daylight are extremely important criteria that were found in all traditional Makki [Mecca-style] houses. I remember that in the harsh summer seasons, my father often took a nap in the sub-zone of the Rawshan [the area between the projected Rawshan and the opening window] because this was where the first fresh air came through ... the Rawshan could distribute air all over the house in the absence of obstacles like closed doors ... " (ArchMM, 2019). 
Rawshans allow incoming breezes to flow through the Rawshan's seat (i.e., subzone) while blocking sunlight. This process is often supported with additional elements, such as stairwells, airshafts, or open doors to strengthen cross-ventilation. Another benefit of Rawshans concerns the evaporative cooling process. As one participant stated, "my mother often placed a jar of water behind the Rawshan lattice, where the air stream was cooled by the evaporation of water from the jars... We could feel cool fresh air ... " (ArchMJ, 2019). Presently, the authors observed that this ventilation function is often not used in older residences that have Rawshans, largely because of the rise of new technologies such as air-conditioning. Additionally, it was observed that most of the Rawshans have been removed and replaced by air conditioning units.

Daylight control measures involve allowing the daylight needed for indoor activities into a structure while preventing excessive heat gain [68]. Due to its climate, solar insolation in Saudi Arabia can result in intense structural heating. The study results show that $57.30 \%$ of survey respondents reported that daylight is an important criterion, $32.92 \%$ thought it was very important, $8.39 \%$ believed it to be moderately important, and $1.40 \%$ believed that it was not important (see Figure 3). In fact, the Rawshan stands as an intriguing option in addressing glare within buildings. All interviewees highlighted the fact that traditional Rawshans are able to regulate the quantity of summer or winter light that enters a room. They block unwanted light, reduce internal heat gains in the summer, and allow sufficient light to enter during the winter.



Figure 3. Ranked characteristics as perceived by study participants.

\subsubsection{Aesthetics}

The quantitative analysis results showed that aesthetics ranked first (78\%) out of all five study criteria. However, eleven decision-makers (six with experience with Rawshans and five without) stated that aesthetics are required in the design of retrofit Rawshans: "... in my opinion, daylight and aesthetics are extremely important criteria. Privacy comes after that. Ventilation and reduced energy use are somewhat important" (CiviMJ, 2019).

\subsection{Rawshan Location}

Both participant groups (i.e., survey respondents and interviewees) were asked three questions regarding Rawshan location and size. The location-related question was divided into two topics: (1) asking those with experience with Rawshans where they typically are located, and (2) their views on optimal room location for installing new Rawshans. In addition, a question related to Rawshan size 
asked if respondents would be willing to buy and install a retrofit Rawshan, and if so, to determine if they would be willing to resize their windows to match the dimensions of a retrofit Rawshan. According to the researchers' observations, Rawshans are typically located on residential building façades that face a street or alley. As discussed previously, the rationale for this location is to allow female residents to observe street-level activities $[8,11]$. This finding related to the survey results regarding the traditional location of Rawshans, as $79.89 \%$ reported that Rawshans are typically found in a living room (i.e., al-Majles or al-Mag'ad), 22.91\% reported the bedroom, 10.61\% stated the kitchen, and $17.88 \%$ reported another location (i.e., al-Majles, al-Mag'ad).

Drawings of traditional Saudi houses that feature Rawshans typically include a maximum of four floors, with each floor serving a specific function. For example, the ground floor typically had multifunctional uses, such as receiving guests or hosting family gatherings. An al-Majles (living room) was usually located on the front facade overlooking a street, with a large window that featured a Rawshan. The al-Mag'ad (guestroom), which was generally located in the ground floor, followed the Arab tradition of guest hospitality and was usually used as a multifunction room, particularly in small houses [68]. However, as the participants ArchMMs, CiviMMs, and CiviMM noted, the al-Mag'ad could also be used as a living room and could feature a Rawshan. As CiviMJ stated, "... most Rawshans were found in either an al-Majles or an al-Mag'ad, or living room, as we call it today. And, I really encourage the instalment of a Rawshan in each zone that women inhabit to allow them to move in freedom with fresh air and natural light without interruptions by pedestrians ....". While all of the decision-makers agreed that an al-Majles would be the best location to install a retrofit Rawshan, some of them stated that they would prefer to locate this feature in bedrooms, kitchens, or both.

\subsection{Electricity Bills}

For most residential structures, energy consumption is an important factor that should be taken into account for the first stage in designing buildings [70]. In Saudi Arabia, the residential building sector presently consumes more than 50\% of the nation's electricity production [71]. However, in 2017, the Saudi government cut subsidies on electricity, water, and petroleum consumption, and recently introduced a $5 \%$ value-added tax. A comparison of the research findings from the survey and decision-maker data shows that most of the survey participants reported higher monthly electricity costs, and the interviewees generally agreed that their electric bills have increased.

To further investigate this phenomenon, the survey participants were asked about the amount of their monthly electric bills in Saudi riyals (SR). The results show that $7.73 \%$ of the participants reported that they pay less than 200 SR (GBP 43.5), $16.69 \%$ pay 201-300 SR (GBP $43.70-65.22$ ), $14.22 \%$ pay $301-400$ SR (GBP 65.43-86.96). A total of $25.04 \%$ pay $401-600$ SR (GBP $87.17-130.43$ ), $14.84 \%$ pay $601-800$ SR (GBP 130.65-173.91), while 21.48\% pay more than 800 SR (GBP 173.91) per month, as shown in Figure 4. With respect to this topic, one of the interviewees stated, “... I believe that as the Industrial Revolution and new technologies reached us, our style, our urban planning and our home designs have totally changed. While this was acceptable on one hand, on the other, we now miss our traditional culture, our traditional homes and even our small streets [i.e., alleys] ... . Regardless if subsidises are cut by the government, in our traditional homes we couldn't use too much energy because of their construction, effective shading devices [i.e., Rawshans] and number of rooms ... " (UrbaMM, 2019). As another of the decision-makers stated, " .. before, we used too much electricity and paid less money. By today, after cutting off the subsidies, we still continue to consume energy, but were shocked by the first bill. It was the highest cost ever ... . But, it was a good idea to cut off the subsidies to force us to control our energy consumption and learn how to adapt ...." (CiviMM, 2019). Therefore, the study results show that twenty experts emphasized energy consumption as the most important criterion. 


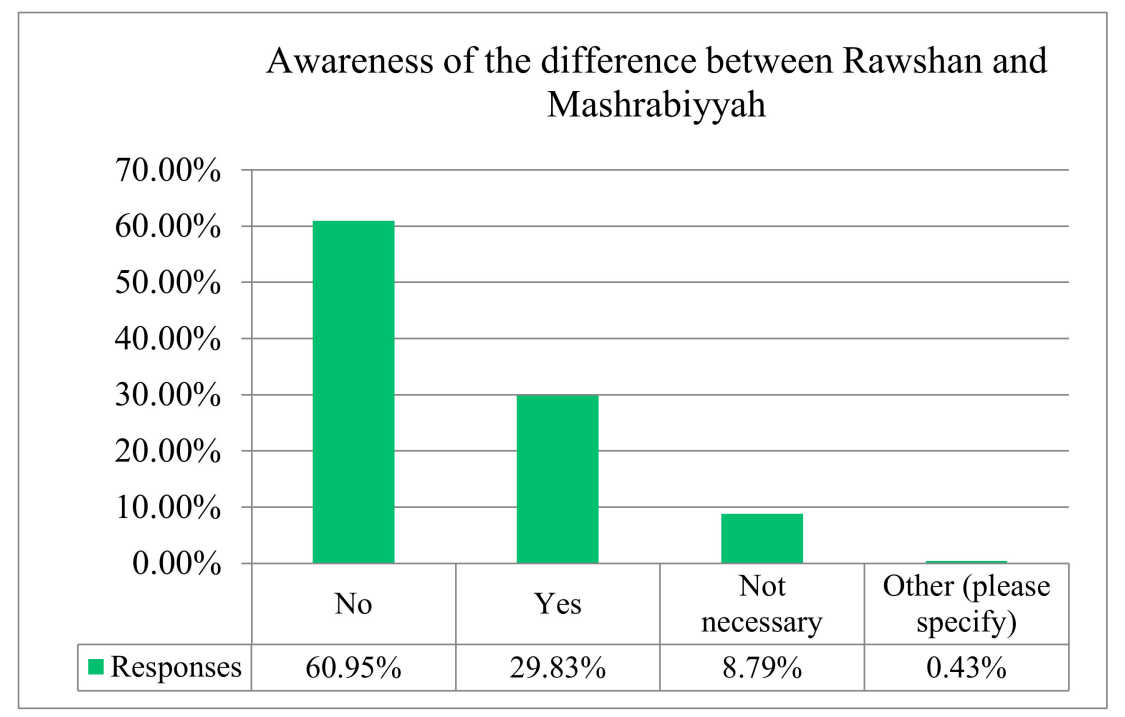

Figure 4. The difference Between Rawshan and Mashrabiyyah.

Architectural drawings show that traditional Saudi homes featured 50-60 cm thick load-bearing walls made of stone that were reinforced with horizontal wooden elements (Tajlilat) spaced at about a $1 \mathrm{~m}$ interval. These walls were then coated with a thick layer of lime-based plaster (locally referred to as Nurah) and painted with a lime wash [68]. Because of the low thermal conductivity of the walls, they were effective in blocking heat transfer. As respondent ArchMJ stated, " ... I agree exterior wall materials and thickness plays a significant role in thermal comfort for residents, and the use of Rawshans helped create indoor air flow and ventilation ... all without any air conditioning ... " (ArchMJ, 2019).

A descriptive analysis of the dependent variables along with the independent variables [72] is given in Table 8, representing the percentage of responses for each option on the 5-point scale. Mean and standard deviation (SD) of responses were computed for each item. As summarized in Table 9, gender has a significant difference on perception about ventilation and energy consumption i.e., males prefer to have a comfortable indoor environment (ventilation), whereas, females are more keen to reduce energy consumption. Therefore, Saudi women's lifestyle nowadays has been impacted by the new updates of Saudi Arabia government systems. Preference order of privacy, daylight, and aesthetic are unanimous by both genders about $-3,4$, and 2, respectively. From the results, it could be summarized that the participants found Fathy [7] five criteria-light control, humidity control, air flow regulation, temperature regulation, and visual privacy-to be useful as a foundation for designing new retrofit Rawshans.

Table 8. Descriptive analysis of the dependent variables (criteria) along with independent variables (Gender).

\begin{tabular}{|c|c|c|c|c|c|c|c|c|c|c|}
\hline \multirow{2}{*}{ Gender } & \multirow{2}{*}{ Criteria } & \multicolumn{5}{|c|}{ Response *\% } & \multirow{2}{*}{ Total } & \multirow{2}{*}{ Mean } & \multirow{2}{*}{ S. D } & \multirow{2}{*}{ Preference Order } \\
\hline & & 1 & 2 & 3 & 4 & 5 & & & & \\
\hline \multirow{5}{*}{ Male } & Privacy & 64.9 & 23.6 & 10.1 & 1.1 & 0.3 & 365 & 1.84 & 0.74 & 3 \\
\hline & Daylight & 54.7 & 34.3 & 9.1 & 1.9 & 0 & 364 & 1.58 & 0.73 & 4 \\
\hline & Ventilation & 62.7 & 23.3 & 11.2 & 2.2 & 0.5 & 365 & 1.55 & 0.82 & 1 \\
\hline & Reducing Energy & 61.3 & 28.8 & 9.1 & 0.3 & 0.5 & 364 & 1.50 & 0.72 & 5 \\
\hline & Aesthetic & 43.8 & 36.2 & 18.9 & 0.8 & 0.3 & 365 & 1.77 & 0.80 & 2 \\
\hline \multirow{5}{*}{ Female } & Privacy & 56.2 & 32.7 & 10.0 & 1.1 & 0 & 281 & 1.6 & 0.72 & 3 \\
\hline & Daylight & 60.7 & 31.1 & 7.5 & 0.7 & 0 & 280 & 1.5 & 0.67 & 4 \\
\hline & Ventilation & 71.2 & 23.1 & 4.6 & 0.7 & 0.4 & 281 & 1.36 & 0.64 & 5 \\
\hline & Reducing Energy & 54.8 & 28.3 & 15.4 & 1.4 & 0 & 279 & 1.63 & 0.79 & 1 \\
\hline & Aesthetic & 43.8 & 42.0 & 12.5 & 1.8 & 0 & 281 & 1.72 & 0.75 & 2 \\
\hline
\end{tabular}

* Response scales are as follows: 1 = extremely important; 2 = very important; 3 = moderately important; 4 = not so important; and $5=$ not at all important. 
Table 9. Spending time in front of the window to see outside while maintaining privacy.

\begin{tabular}{cc}
\hline Options & Responses \\
\hline Close the curtains & $54.40 \%$ \\
Move away from a window until pedestrians depart & $13.91 \%$ \\
Installing a Rawshan & $23.03 \%$ \\
Do nothing & $7.11 \%$ \\
Other & $1.55 \%$ \\
\hline
\end{tabular}

\subsection{Rawshans vs. Mashrabiyyahs}

While the Rawshan is a familiar architectural element in most Arabic countries, many nations have their own term for this element. For example, in Bahrain, a Rawshan is known as a Mashrabiyyah, and in Iraq, it is called a Shanasheel. The Yemeni refer to a Rawshan as a Takrima (meaning full of holes), and in Algeria, a nation with strong elements of Turkish architecture, it is called a Gublae, while in Tunis it is called a Barmalqi. However, Salloum [11] illustrated the similarities and differences between Rawshans and Mashrabiyyah. The author maintained that a Mashrabiyyah is considered part of a Rawshan, namely its window screen. From the results, it was found that a significant number of respondents (60.95\%) did not know the difference between a Rawshan and a Mashrabiyyah. Moreover, most of the interviewees reported that they were aware of the difference between a Rawshan and a Mashrabiyyah, and two participants stated that while they knew that Rawshans and Mashrabiyyahs were different, they did not know the specifics of these differences. One stated, "... I do not know what the difference between them architecturally is, but I know the shape of these elements. A Rawshan is a box, and a Mashrabiyyah is arabesque panels" (CiviMJ, 2019), and another said that "... I agree that one of them can accommodate two people in its sub-zone" (CiviMM, 2019).

\subsection{Causing the Decline in Rawshans}

The survey findings revealed that $38.7 \%$ of respondents believed that the Rawshan has entirely lost its identity, $20.5 \%$ suggested that its identity has largely been lost, $25.6 \%$ suggested that its identity has been moderately lost, and only $5 \%$ of respondents reported that the Rawshan's identity has not been lost at all (see Figure 5). Moreover, all respondents other than the decision-makers agreed that the Rawshan has lost its identity and is now used only for decorative purposes. In addition, the analysis results represented another subcode (emulation) found in the subtext of terms such as copying, mimicking, pasting, and imitating.

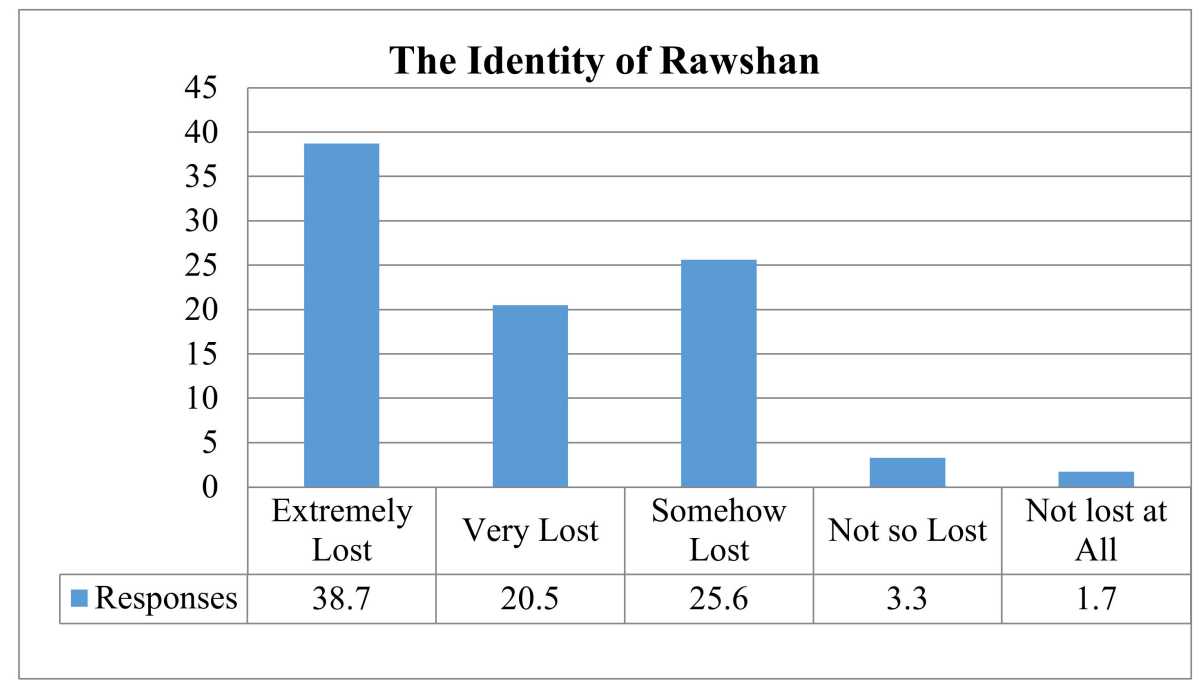

Figure 5. The identity of Rawshan as perceived by participants. 
The method of "copying and pasting" architectural practices has resulted in a decline in the functional design of Saudi Arabian homes in general and of the use of Rawshans in particular. Most new Rawshans are constructed only for cosmetic appearance and mimic the traditional Rawshan form without following its traditional function. ArchMM, ArchMJ, and UrbaMM described the current situation with respect to Rawshans as one of "exhibitionism and extravagance", which are common phenomena in selecting façade designs for most Saudi residences. ArchMJ linked the current meaning of the Rawshan to the importance and appearance of wealth, even though Islamic cultures favour simplicity and modesty over exhibitionism and extravagance. Furthermore, this attention to appearance can lead homeowners to use environmentally undesirable details.

Furthermore, when one of the authors was working in Mecca's Building Permits Department, he saw that most architecture offices employ a large proportion of foreign-born staff, who have different customs and traditions that influence the design of Saudi residences. One of the interviewees agreed with this assessment and stated: "... we have different clients who are wealthy and moderate. The wealthy clients don't care about how much they pay, and they want their homes to impress the person looking at them. In these cases, architects play a role in helping human comfort and supporting the environment. Some foreign architects give clients logical solutions, and others do not. Many agree with unreasonable client opinions in order to collect their fees. Otherwise, they add custom and traditional touches ... " (ArchMM, 2019). This process has allowed the use of Rawshans to decline, as homeowners copy the designs of their neighbors regardless of function. Thus, as ArchMM (2019) stated, Rawshans designed without their intended function can spread like a "domino effect".

\subsection{Factors Encouraging the Purchase of Retrofit Rawshan}

Participants were also asked about reviving the Rawshan and its traditional functions as an architectural element. The study results show that $41.8 \%$ of participants strongly agreed, and $36.5 \%$ agreed on this matter. Furthermore, $8.9 \%$ of participants were neutral concerning this question, and a combined $2.7 \%$ either disagreed or strongly disagreed. In terms of encouraging the use of a new Rawshan, the participants were asked if they would be willing to install a retrofit Rawshan if it was demonstrated to reduce energy consumption, as this feature was not commonly known. As the analysis results show, $37.7 \%$ of participants strongly agreed that they would use a retrofit Rawshan that reduced energy consumption, $36.4 \%$ agreed, $10.3 \%$ were neutral, and $5.6 \%$ disagreed that they would acquire such a device. Furthermore, all expert participants requested that they would use a retrofitted Rawshan design that decreased residential energy consumption and $\mathrm{CO}_{2}$ emissions as well as preserved its historical identity. As one expert stated, "... I would absolutely go for it and buy it. This could help me with the use of artificial lights during daylight hours. I imagine that this could reduce interior lighting use by at least $5 \%$... I I believe while five percent is not much, and we wouldn't feel any change in the monthly budget, it has a nice benchmark annually ...." (UrbaMM, 2019).

In addition, as most of the interviewees have experience with residential energy consumption, they pointed out that building Rawshans is not the only way to reduce home electricity use, and that measures such as insulating walls, floors, and roofs is essential, particularly in hot and arid countries such as Saudi Arabia.

\subsection{Saudi Building Codes}

The Saudi government has few specific regulations for windows or window treatments with respect to the architectural design of residential structures. The government only requires windows to function as passive sources of ventilation and specifies that they must not open towards a neighbor's house at a distance of fewer than two meters (ArchMMs, ArchMJs, and ArchMB). Thus, the researchers included a question in the expert interviews concerning if retrofit Rawshan design should be incorporated into the Saudi Building Code (SBC). The results showed that all interviewees, even those who had no experience with Rawshans, agreed that retrofit Rawshans should be included in the SBC under some conditions. Specifically, five subcodes emerged in the interview data regarding the addition of 
Rawshans to the SBC. These conditions, in descending order of preference, included (a) achieving privacy, (b) reducing energy consumption, (c) increasing homeowner affordability, (d) addressing environmental and human concerns, and (e) ease of maintenance.

(a) The first condition concerned privacy. All of the interviewees stated that any Rawshan retrofit should respect Saudi culture. As ArchMM said, "... I strongly agree on joining my voice to integrate Rawshans into the Saudi Building Code (SBC), but with the condition that they achieve full privacy and necessary lighting requirements ....". Currently, many contemporary solutions exist that achieve full occupant privacy (e.g., operable curtains). Thus, the researchers posed questions designed to evaluate the public perception and expert opinions regarding the actions they take to maintain full privacy when they spend time close to residential windows. As Table 9 and Figure 6 show, $54.4 \%$ of survey respondents reported that they close their curtains in order to maintain privacy, whilst $13.9 \%$ sit away from the window until passers-by depart. Furthermore, $23.03 \%$ of respondents reported that they would be willing to install a Rawshan that would help them to better control daylighting levels and maintain privacy, $7.11 \%$ reported that they typically do nothing, and $1.55 \%$ claimed that they employ other means. As discussed previously, privacy is the most respected factor in Islamic and Arabic countries.

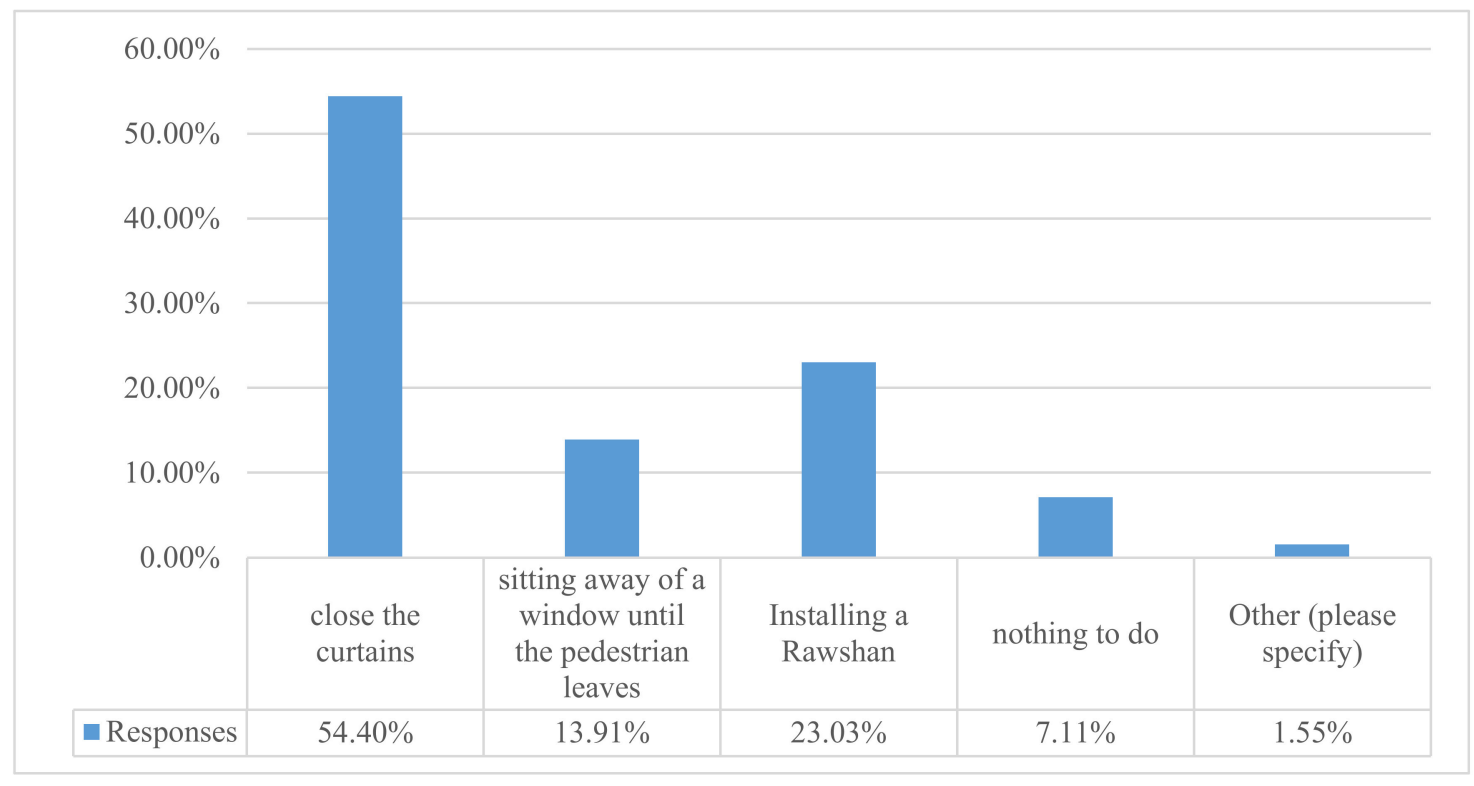

Figure 6. Spending time in front of a window to see outside while maintaining privacy.

(b) The second condition involved reducing energy consumption. All of the experts reported that they understood that energy used by air conditioning systems is the largest source of energy consumption in residential dwellings.

(c) The third condition concerned the price of retrofit Rawshans. Some of the interviewees pointed out that if Rawshans were required by the SBC, they should be relatively affordable in the Saudi market. "To be accepted and included in the Saudi Building Code, besides preserving their identity, they should be affordable for all users ... " (CiviMM, 2019). However, ArchMB stated, "I think if a retrofit Rawshan passed the optimization [process], it wouldn't be a problem [for residents] to pay higher prices because they could see lower costs over time ....".

(d) The fourth condition involved environmental and human benefits, which relate to thermal comfort. One of the decision-makers (ArchMJ), who had experience with traditional Rawshans, reported that "... I'm one who has experienced with a Rawshan in my father's home, and I believe it helped in making comfortable zones... So, I would support adding retrofit Rawshans to the Saudi Building 
Code if they achieved exactly the same goals as traditional Rawshan plus supported the environment and help humans ....".

(e) The fifth condition related to ease of maintenance. This subtheme emerged from interviewees who had lived in a home with a Rawshan. They pointed out that one disadvantage of Rawshans was its opening, which allows dust and insects to enter the home. For example, one maintained that any retrofit Rawshan design should add single pane glazing to its operable windows (ArchMM, 2019).

\section{Limitations of the Study}

The main limitation of the survey was its dependence on participants using a computer to access the Internet to complete the survey. According to the Communications and Information Technology Commission in Saudi Arabia, in 2015, 8.88\% of Saudi Arabians were not using the Internet. Therefore, the study involved only educated in Saudi Arabia, who in 2017 included 81.3\% of the population, according to the Department of Statistics and Information in Saudi Arabia. In terms of Internet access in Saudi Arabia, use by young people is more frequent than by older people [73]; $53.30 \%$ of Saudis use email services, and $7.01 \%$ of the public do not use any Internet services [73]. Additionally, according to the Ministry of Electricity in Saudi Arabia, some villages in suburban areas across Saudi Arabia are not covered by the national electricity grid, relying on local energy sources; thus, those people were not included in the study. Nevertheless, despite these limitations, the study reached the majority of towns and cities across Saudi Arabia.

\section{Conclusions}

In this era of globalization, many researchers assert that contemporary Middle Eastern architecture suffers from an identity crisis, mainly due to the absence of a consistent understanding and application of the principles connected with vernacular environments and precedents. As found in this study, architects should rethink the values and reconsider the principles that once elevated vernacular architecture in the Middle East and insisted that nurturing a suitable architectural identity in the region was crucial. This study provides a comprehensive investigation for a Rawshan vernacular architectural element and includes a quantitative and qualitative study to support the need of reviving the Rawshan in residential buildings in Saudi Arabia. The following recommendations can be made based on the analysis results of the quantitative and interview data.

The trends of "exhibitionist and extravagance culture" have spread in the Saudi community, and a Rawshan has appeared with a high quality of motifs, which means environmental consideration has been faded of the sight for designing a Rawshan. In fact, aesthetics is among the important criteria for a Rawshan. However, in the case of reviving a Rawshan, designers need to take into account other criteria mentioned in this study. Reduced energy consumption (i.e., electricity bills) was found to be the second most important criterion, which should be taken into account for the first stage in designing a Rawshan (75\% with a mean score of 1.56), perhaps due in part to the Saudi government's decision to eliminate its electricity subsidies. Although there is a high level of acceptance for reviving the Rawshan as found from the results, reducing energy consumption does not depend on a Rawshan itself, but it needs other supporting factors such as wall, floor, and roof insulations. As one of the experts stated, " ... if we imagine installing a retrofit Rawshan in one room (e.g., a living room), which is a room that does not consume much energy, it wouldn't reduce building consumption that much. It might save $1-3 \%$ in this one room ....".

The survey results show that daylight ranked third out of five (71\%) among the criteria. This finding was corroborated by most of the interviewees, who agreed with daylight being the most significant criterion.

Privacy plays an important role in Islamic nations in general and in Saudi society in particular. On the other hand, the results of this research showed that the survey respondents ranked privacy fourth out of five criteria. Cultures can merge through foreign architects as stated in Section 5.5, as they exert an influence through their designs. In addition, the Ministry of Education in Saudi Arabia has 
provided more than 93,000 scholarships which has participated to transferring different cultures to the country. Therefore, the privacy might be affected by the culture coalescing. However, this result does not mean that privacy is not required in Saudi homes; after all, it is still required by the Islamic law.

The survey results show that respondents ranked ventilation as the fifth preferable criterion. Furthermore, the decision-makers recommended that adding additional elements to Rawshans, such as glazing, could have a significant effect on HVAC (heating, ventilation, and air conditioning) systems.

This research will inform follow-on interventions in the design and use of vernacular architectural elements in the region. In particular, it will promote the use of these elements for their intrinsic attributes, such as for improving the perceived comfort of occupants as well as reducing their carbon footprint, as opposed to merely mimicking ancestral construction traditions. Moving forward, the authors are building on the findings of this study to design an optimized blind system for a Rawshan that is customizable for a range of climates and aspects in Saudi Arabia. As such, future research will investigate the role of the Rawshan in promoting energy efficiency in domestic buildings in the region. This will be reported in a follow-on publication.

Author Contributions: Conceptualization, R.A., M.W.A. and Y.R.; methodology, R.A., M.W.A. and Y.R.; software, R.A.; validation, R.A., M.W.A. and Y.R.; formal analysis, R.A.; investigation, R.A.; resources, R.A.; data curation, R.A.; writing-original draft preparation, R.A.; writing—review and editing, M.W.A. and Y.R.; visualization, R.A.; supervision, Y.R.; project administration, R.A.; funding acquisition, R.A. All authors have read and agreed to the published version of the manuscript.

Funding: This research received no external funding.

Conflicts of Interest: The authors declare no conflict of interest.

\section{References}

1. Oliver, P. Encyclopedia of Vernacular Architecture of the World; Cambridge University Press: Cambridge, UK, 1997.

2. Rapoport, A. Vernacular Architecture. Curr. Chall. Environ. Soc. Sci. 1990, 24, 30-45.

3. Rapoport, A. Defining vernacular design. In Vernacular Architecture Paradigms of Environmental Response; Turan, M., Ed.; Gower Publishing Company: Avebary, UK, 1990.

4. Aldossary, N.A.; Rezgui, Y.; Kwan, A. Domestic energy consumption patterns in a hot and arid climate: A multiple-case study analysis. Renew. Energy 2014, 62, 369-378. [CrossRef]

5. Tawayha, F.A.; Braganca, L.; Mateus, R. Contribution of the vernacular architecture to the sustainability: A comparative study between the contemporary areas and the old quarter of a Mediterranean City. Sustainability 2019, 11, 896. [CrossRef]

6. Asquith, L.; Vellinga, M. Vernacular Architecture in the 21st Century: Theory, Education and Practice; Taylor \& Francis: Abingdon, UK, 2006.

7. Fathy, H. Natural Energy and Vernacular Architecture; University of Chicago Press: Chicago, IL, USA, 1986.

8. Hariri, M. Design of Rowshan and its importance to the dwelling. J. Umm-Al-Qura Univ. 1992, 3, $175-237$.

9. Al-Shareef, F.M. Natural Light Control in Hadjazi Architecture: An Investigation of the Rowshan Performance by Computer Simulation. Ph.D. Thesis, University of Liverpool, Liverpool, UK, 1996.

10. Curl, J.S.; Wilson, S. The Oxford Dictionary of Architecture; Oxford University Press: Oxford, UK, 2015.

11. Salloum, A. "EL RAWASHIN" OF JEDDAH SAUDI ARABIA. In Passive and Low Energy Architecture; Elsevier: Amsterdam, The Netherlands, 1983; pp. 245-252.

12. Alitany, A. A New Strategy of ICT Integrated Methodologies for 3D Documentation: A Case Study of the Projected Wooden Windows (The Roshans) in the Historical City of Jeddah (Saudi Arabia). Ph.D. Thesis, Universitat Politècnica de Catalunya, Barcelona, Spain, 2014.

13. Fadan, Y.M. The Development of Contemporary Housing in Saudi Arabia (1950-1983): A Study in Cross-Cultural Influence under Conditions of Rapid Change; Massachusetts Institute of Technology: Cambridge, MA, USA, 1983.

14. Gelil, N.A. A new mashrabiyya for contemporary Cairo: Integrating traditional latticework from Islamic and Japanese cultures. J. Asian Archit. Build. Eng. 2006, 5, 37-44. [CrossRef]

15. Aljawder, H.M.H. Residential Window: Daylight vs. Visual Privacy; University of Sydney: Camperdown, Australia, 2014. 
16. Almurbati, N.; Headley, D.; Ford, P.; Taki, A. From manual to hybrid, parametric Mashrabiya: Digital workflow for the re-envisioning and conservation of Eastern architectural screens and the engagement of digital tectonics. Int. J. Architecton. Spat. Environ. Des. 2016, 10, 29-39. [CrossRef]

17. Kenzari, B.; Elsheshtawy, Y. The ambiguous veil: On transparency, the Mashrabiy'ya, and architecture. J. Archit. Educ. 2003, 56, 17-25. [CrossRef]

18. Samuels, W. Performance and Permeability: An investigation of the Mashrabiya for Use within the Gibson Desert. Master's Thesis, Victoria University of Wellington, Wellington, New Zealand, 2011.

19. Aljofi, E. The potentiality of reflected sunlight through Rawshan screens. In Proceedings of the International Conference Passive and Low Energy Cooling for the Built Environment, Santorini, Greece, 19-21 May 2005; pp. 817-822.

20. Gelil, M.N.A.; Badawy, N.M. Simulated comparative investigation of the daylight and airflow of the conventional Egyptian shutter 'sheesh' and a proposed latticework device 'new mashrabiyya'. Indoor Built Environ. 2015, 24, 583-596. [CrossRef]

21. Karamata, B. Concept, Design and Performance of a Shape Variable Mashrabiya as a Shading and Daylighting System for Arid Climates. In Proceedings of the 30th PLEA Conference-Sustainable Habitat for Developing Societies, CEPT University Ahmedabad, Ahmedabad, India, 16-18 December 2014.

22. Chan, Y.-C.; Tzempelikos, A. Efficient venetian blind control strategies considering daylight utilization and glare protection. Sol. Energy 2013, 98, 241-254. [CrossRef]

23. Sherif, A.; El-Zafarany, A.; Arafa, R. External perforated window Solar Screens: The effect of screen depth and perforation ratio on energy performance in extreme desert environments. Energy Build. 2012, 52, 1-10. [CrossRef]

24. Francesca, M.; Marco, M. Energy and daylighting interaction in offices with shading devices. In Proceedings of the 1st IBPSA Italy Conference, Bolzano, Italy, 30 January-1 February 2013; pp. 385-393.

25. Freewan, A.A. Impact of external shading devices on thermal and daylighting performance of offices in hot climate regions. Sol. Energy 2014, 102, 14-30. [CrossRef]

26. Erell, E.; Kaftan, E.; Garb, Y. Daylighting for visual comfort and energy conservation in offices in sunny regions. In Proceedings of the Passive and Low Energy Architecture Conference, Ahmedabad, India, 16-18 December 2014.

27. Kotbi, A. Perforated Solar Screens to Optimize Daylighting and Maintain Privacy in Girls' Schools in Hot Arid Areas: The Case of Saudi Arabia: Investigating Parameters of Perforated Solar Screens. Ph.D. Thesis, Cardiff University, Cardiff, UK, 2019.

28. Shin, H.Y.; Lee, Y.; Jang, M.; Moon, K.H.; Kim, J.T. Daylighting performance on venetian blind for healthy apartment housing. In Proceedings of the First International Conference on Sustainability and the Future FISC 2010 Proceedings of the First International Conference on Sustainability and the Future: Future Intermediate Sustainable Cities: A Message to Future Generations, Cairo, Egypt, 23-25 November 2010.

29. Sidawi, B. A Conceptual Analytic Model of the Vocabulary of the Islamic Architectural Heritage. Emir. J. Eng. Res. 2012, 17, 47-56.

30. Mahmoud, A.H.A.; Elghazi, Y. Parametric-based designs for kinetic facades to optimize daylight performance: Comparing rotation and translation kinetic motion for hexagonal facade patterns. Sol. Energy 2016, 126, 111-127. [CrossRef]

31. Elkhatieb, M.; Sharples, S. Climate Adaptive Building Shells for Office Buildings in Egypt: A Parametric and Algorithmic Daylight Tool. In Proceedings of the SBE16 Dubai, Dubai, UAE, 17-19 January 2016; pp. 1-8.

32. Alelwani, R.; Ahmad, M.; Rezgui, Y.; Kwan, A. Rawshan: Environmental Impact of a Vernacular Shading Building Element in Hot Humid Climates. In Proceedings of the 2019 IEEE International Conference on Engineering, Technology and Innovation (ICE/ITMC), Valbonne Sophia-Antipolis, France, 17-19 June 2019; pp. 1-6.

33. Huang, H.-M. Do print and Web surveys provide the same results? Comput. Hum. Behav. 2006, 22, 334-350. [CrossRef]

34. Rezgui, Y.; Miles, J. Exploring the potential of SME alliances in the construction sector. J. Constr. Eng. Manag. 2010, 136, 558-567. [CrossRef]

35. Statistics, S.A.f. (Saudi Authority for Statistics). Available online: https://www.stats.gov.sa/en/911-0 (accessed on 26 September 2019). 
36. Kruth, J.-P.; Leu, M.-C.; Nakagawa, T. Progress in additive manufacturing and rapid prototyping. Cirp Ann. Manuf. Technol. 1998, 47, 525-540. [CrossRef]

37. SurveyMonkey. (SurveyMonkey). Available online: https://www.surveymonkey.com/mp/sample-sizecalculator/ (accessed on 13 March 2019).

38. Denzin, N.K.; Lincoln, Y.S. The Sage Handbook of Qualitative Research; Sage: London, UK, 2011.

39. Cohen, L.; Manion, L.; Morrison, K. Surveys, longitudinal, cross-sectional and trend studies. In Research Methods in Education, 7th ed.; Routledge: Abingdon, UK, 2011; pp. 261-264.

40. Fadli, F.; AlSaeed, M. A Holistic Overview of Qatar's (Built) Cultural Heritage; Towards an Integrated Sustainable Conservation Strategy. Sustainability 2019, 11, 2277. [CrossRef]

41. Bryman, A. Social Research Methods; Oxford University Press Inc.: New York, NY, USA, 2012.

42. Aldossary, N.A.; Rezgui, Y.; Kwan, A. An investigation into factors influencing domestic energy consumption in an energy subsidized developing economy. Habitat Int. 2015, 47, 41-51. [CrossRef]

43. Almerbati, N. Hybrid Heritage: An Investigation into the Viability of 3D-printed Mashrabiya Window Screens for Bahraini Dwellings. Ph.D. Thesis, De Montfort University, Leicester, UK, 2016.

44. Rajapaksa, D.; Islam, M.; Managi, S. Pro-environmental behavior: The role of public perception in infrastructure and the social factors for sustainable development. Sustainability 2018, 10, 937. [CrossRef]

45. Bravo, G.; Pardalis, G.; Mahapatra, K.; Mainali, B. Physical vs. aesthetic renovations: Learning from Swedish house owners. Buildings 2019, 9, 12. [CrossRef]

46. Stanton, J.M. An empirical assessment of data collection using the Internet. Pers. Psychol. 1998, 51, 709-725. [CrossRef]

47. Weible, R.; Wallace, J. Cyber research: The impact of the Internet on data collection. Mark. Res. 1998, 10, 19.

48. Collins, H. Creative Research: The Theory and Practice of Research for the Creative Industries; Bloomsbury Publishing: London, UK, 2018.

49. IBM Corp, N. IBM SPSS Statistics for Windows, Version 22.0; IBM Corp.: Armonk, NY, USA, 2013.

50. Cronbach, L.J. Coefficient alpha and the internal structure of tests. Psychometrika 1951, 16, 297-334. [CrossRef]

51. Webb, N.M.; Shavelson, R.J.; Haertel, E.H. 4 reliability coefficients and generalizability theory. Handb. Stat. 2006, 26, 81-124.

52. Alshamrani, O.; Alshibani, A.; Alogaili, M. Analytic hierarchy process \& multi attribute utility theory based approach for the selection of lighting systems in residential buildings: A case study. Buildings 2018, 8, 73.

53. Tavakol, M.; Dennick, R. Making sense of Cronbach's alpha. Int. J. Med. Educ. 2011, 2, 53. [CrossRef]

54. Makki, A.A.; Mosly, I. Factors Affecting Public Willingness to Adopt Renewable Energy Technologies: An Exploratory Analysis. Sustainability 2020, 12, 845. [CrossRef]

55. Frank, O.; Snijders, T. Estimating the size of hidden populations using snowball sampling. J. Off. Stat. Stockh. 1994, 10, 53.

56. Nejat, A.; Cong, Z.; Liang, D. Family structures, relationships, and housing recovery decisions after Hurricane Sandy. Buildings 2016, 6, 14. [CrossRef]

57. Gosselin, A.; Blanchet, P.; Lehoux, N.; Cimon, Y. Collaboration Enables innovative timber structure adoption in construction. Buildings 2018, 8, 183. [CrossRef]

58. Illenberger, J.; Flötteröd, G. Estimating network properties from snowball sampled data. Soc. Netw. 2012, 34, 701-711. [CrossRef]

59. Singh, P.; Pandey, A.; Aggarwal, A. House-to-house survey vs. snowball technique for capturing maternal deaths in India: A search for a cost-effective method. Indian J. Med Res. 2007, 125, 550. [PubMed]

60. Mosly, I.; Makki, A.A. Current status and willingness to adopt renewable energy technologies in Saudi Arabia. Sustainability 2018, 10, 4269. [CrossRef]

61. Beach, T.H.; Rezgui, Y.; Li, H.; Kasim, T. A rule-based semantic approach for automated regulatory compliance in the construction sector. Expert Syst. Appl. 2015, 42, 5219-5231. [CrossRef]

62. Ltd, Q. NVivo Qualitative Data Analysis Software; QSR International Pty Ltd.: Doncaster, Australia, 2014.

63. Hariri, M.M. Housing in central Makkah: Influence of Hajj. Ph.D. Thesis, Newcastle University, Newcastle, UK, 1986.

64. Almerbati, N.; Ford, P.; Taki, A.; Dean, L. From Vernacular to Personalised and Sustainable. In ACROSS: Architectural Research through to Practice, 48th International Conference of the Architectural Science Association $(A N Z A S c A)$; Madeo, F., Schnabel, M.A., Eds.; The Architectural Science Association (ANZAScA): Sydney, Austrailia; Genova University Press: Genova, Italy, 2014; pp. 479-490. 
65. Alenazy, T.H. The Privacy and Social Needs of Women in Contemporary Kuwaite Homes. Master of Fine Arts. Thesis, Florida State University, Tallahassee, FL, USA, 2007.

66. Miles, M.B.; Huberman, A.M.; Huberman, M.A.; Huberman, M. Qualitative Data Analysis: An Expanded Sourcebook; University of Michigan: Ann Arbor, MI, USA, 1994.

67. Rezgui, Y.; Marks, A. Information security awareness in higher education: An exploratory study. Comput. Secur. 2008, 27, 241-253. [CrossRef]

68. Al-Lyaly, S.M.Z. The Traditional House of Jeddah: A Study of the Interaction between Climate, Form and Living Patterns. Ph.D. Thesis, University of Edinburgh, Edinburgh, UK, 1990.

69. Santamouris, M.; Asimakopoulos, D. Passive Cooling of Buildings; Earthscan: London, UK, 1996.

70. Brounen, D.; Kok, N.; Quigley, J.M. Residential energy use and conservation: Economics and demographics. Eur. Econ. Rev. 2012, 56, 931-945. [CrossRef]

71. Alnaser, W.E.; Alnaser, N.W. The status of renewable energy in the GCC countries. Renew. Sustain. Energy Rev. 2011, 15, 3074-3098. [CrossRef]

72. Rotimi, F.E.; Tookey, J.; Rotimi, J.O. Evaluating defect reporting in new residential buildings in New Zealand. Buildings 2015, 5, 39-55. [CrossRef]

73. CITC. The Results of the Study of the Survey of the Communications and Information Technology Market, 5th ed.; Individuals/Families Report; Commission, C.a.I.T. Communications and Information Technology Commission: Riyadh, Saudi Arabia, 2015; pp. 28-50.

(C) 2020 by the authors. Licensee MDPI, Basel, Switzerland. This article is an open access article distributed under the terms and conditions of the Creative Commons Attribution (CC BY) license (http://creativecommons.org/licenses/by/4.0/). 